\title{
Study on Seniors Tourists Market Based on STP Strategy SUN Jing ${ }^{\mathrm{a},{ }^{*},}$, MA Chao ${ }^{\mathrm{b}}$, ZHANG Yi Xin $^{\mathrm{c}}$ \\ School of Tourism and Cuisine, Harbin University of Commerce, Harbin, China a460014175@qq.com, bmybestchris@163.com, c532893102@qq.com
}

Key words: senior tourism, market, STP

\begin{abstract}
With the further extent of aging, it has been a focus for the whole society that enable seniors to have a peaceful and enjoyable time after retirement. Traveling is regarded as the major method to fulfill seniors spiritual demands and enrich their life, but there are still some problems with the seniors tourism market such as low quantity, poor quality and lack of features. Therefore, this paper attempts to put forward a few feasible suggestions on the healthy development for the seniors tourism market based on the discussion on the characteristics of demands of seniors traveling by STP strategy.

According to the Suggestions on Promoting Reform of Tourism Industry put forward by the State Council in 2014, the rural tourism, study tourism and seniors tourism should be stimulated by great effort. Regulations of service of seniors tourists by travel services have been issued by CNTA on 1st September 2016. These documents show that the seniors tourists have been the focus for both the tourism industry and the whole society. It is of significance to enhance the wellbeing of seniors by promoting seniors tour to build a stable seniors tourism market.
\end{abstract}

\section{Overview of Seniors Population in China}

1.1 The Proportion of the Aged Population Is Growing Fast with high Rate According to the results of the sixth national census in 2010, China's elderly population aged over 60 reached 178 million, accounting for $13.33 \%$ of the total population. Over the age of 65 reached 119 million, accounting for $8.93 \%$ of the total population.

The population of Chinese seniors is not only large but also with rapid growth. The percentage of seniors population over 65 years is $6.96 \%$ in $2000,8.87 \%$ in $2010,10.8 \%$ by the end of 2016 . By 2020, the number of seniors people aged 65 and over will reach 167 million, accounting for $24 \%$ of the world's 698 million. One of the world's four seniors people is Chinese.

\subsection{Uneven Distribution of Seniors Population}

1.2.1 Uneven Distribution of Time Although in accordance with the standards of the United Nations, China has entered the aging society. But the extent of aging is not only the same in different regions during different times.

1.2.2 Uneven Distribution in Space The uneven distribution in space of China's seniors population is quite obvious. Firstly, the difference between urban and rural areas is obvious. Secondly, the gap between the provinces in significant, the highest degree of seniors in Chongqing reached $17.42 \%$, while the lowest in the Tibet Autonomous Region is only $7.67 \%$, which shows more than twice the difference.

\section{Analysis on the Demand of Seniors Tourists Market}

2.1 Increased Leisure Time and Demand After retirement many seniors people find nothing to do when they release from their positions with sudden increase in leisure time. In order to fill the spare time, travelling has become an important way to meet the spiritual needs.

2.2 Pay Attention to Safety The seniors tourists are critical to the safety and quality of service requirements during traveling. On the one hand, they require a slow, comfort, safety trip that combining work with rest; the other hand, the catering, accommodation requirements should be arranged with special concerns. 
2.3 Sensitive to Price Many seniors still maintain a saving living habit with growing income and reduced life pressure. At the same time, due to China's traditional culture and the current situation, some seniors will continue to offer financial support to their children. In this case, most seniors are sensitive to price during traveling with lower expenditure.

\section{Status Quos of the Seniors Tourism in China}

3.1 Limited Tourism Products for Seniors Due to the poor physical condition, the low level of consumption, the relatively high security requirements, many travel services fail to introduce the tailor-made tourism products for the seniors by considering the cost and profit factors. Instead, they promoted the ordinary tourism products such as so-called "sunset red" routes, which shows no differences and can not meet the needs of the seniors effectively.

3.2 Lack of Features with no Distinction After careful study it can be clearly found that some of the seniors products are more distinctive, while others are nothing more than the so-called "sunset red" "silver hair" "our parents" that show no differences between ordinary tourism products without any features.

3.3 Low Quality with Insufficient of Market Segmentation In fact, seniors have various traveling demands. And the existing market products did not take into account the needs of the elderly differences. Firstly, most tourist attractions, tourist vehicles, tourist hotels and other tourist reception facilities are not specifically designed for the seniors. Secondly, the service is not sufficient. Thirdly, security measures are not in place. At the same time, in order to attract seniors tourists, some travel services significantly reduce the tour fee by reducing the safety standards and service quality, which inevitably increase the risk of travel for the seniors tour groups.

\section{Promoting the Seniors Tourism Market Based on STP Strategy}

The author proposed to conduct research on the seniors tourism market development and product design in accordance with STP strategy to design more reasonable tourism products and routes, establish the seniors tourism brand, regulate the seniors tourism market.

4.1 Segmenting In line with the market segmentation method, the seniors tourism market can be segmented as follows:

Based on the location, it can be divided into: urban elderly and rural elderly; the elderly and the elderly in the north; by age, can be divided into: the elderly (75 years old), middle-aged (67-75 years old) Old age (60-66 years old); by occupation (before retirement), can be divided into: teachers, doctors, civil servants, employees, individual operators, etc .; by sex, can be divided into: elderly male and elderly female; (Pension): can be divided into high-income elderly, middle-income elderly and low-income elderly; by way of tourism, can be divided into groups of elderly market, individual elderly market; according to tourism purposes, vacation, health, VFR, nostalgia, religion and other tourist markets.

4.2 Targeting According to the goal selection theory, there are three strategic options:

4.2.1 No Difference Strategy: Only Design and Promote One Seniors Tourism Product to Face the Whole Seniors Tourism Market. This strategy reduces the cost of product development and helps increasing target audiences. At present, most of the tourism enterprises of the tourism market basically adopt the target market strategy.

4.2.2 Differentiation Strategy: Develop and Design Different Seniors Tourism Products to Meet the Needs of Different Elderly Market Segments. This strategy can meet the needs of different seniors market segments, highlight the characteristics of tourism products, and improve customer satisfaction effectively. According to which travel network launched "Changchun Beijing 65 evening sunset red tour", divided the travel product into comfortable, high-grade and luxury respectively for low-income, middle income and high income elderly tourism market.

4.2.3 Centralized Strategy: Only Develop and Design One Seniors Tourism Product for One Seniors Market Segments This strategy allows enterprises to focus on limited human, 
material and other resources, to develop a product of distinctive features, which can meet the needs of an elderly, market segments effectively.

4.3 Positioning The seniors tourism products market can be positioned mainly in the following ways:

4.3.1Seek Differences. Seeking Differences Is An Effective Way to Reduce the Degree of Homogenization of Products and to Resolve Market Competition.

4.3.1.1 To seek service differences. On account of the physiological characteristics and physical condition of the seniors, reduce the intensity to ensure 8-hours sleeping, abandon the sheep traveling. Contact their relatives by wechat, report the itinerary, so that visitors and their families are assured.

4.3.1.2 To seek staff differences. From the team leader, to guide the hotel staff and other services to ensure that the seniors tourists service personnel to do meticulous training to show enough care and patience.

4.3.1.3 To seek differences in route arrangements. Different from the ordinary tourism products, with "fast journey slow sightseeing," the rhythm of the seniors tourists should be slow by delaying the pace of travel and reducing tourism intensity, so that the seniors can travel leisurely to avoid the "scenic in the old march "phenomenon.

4.3.2. Highlight the Unique Selling Point An elderly tourism product should have a unique selling point, in order to demonstrate product characteristics with strong market competitiveness. It can be selected from the target market demand situation by considering the design of a unique selling point. With a unique selling point to define the precise market positioning can highlight the product characteristics and tastes to attract the attention of the target market.

\section{Acknowledgement}

This research was financially supported by Project of philosophy and social sciences Heilongjiang Province (Grant NO. 13E031), and Discipline project of Harbin University of Commerce: Study on the modern service industry to support Longjiang revitalization (Grant NO. hx2016001).

\section{References:}

[1] S.D. Lou, China's seniors tourism market development research, Journal of the CPC Zhengzhou Municipal Committee, vol.5, pp. 40-42, 2012.

[2] J. Liu, H.L. Han, China's seniors tourism market development and industrial structure adjustment, Guangxi University Journal of Philosophy and Social Sciences, vol.3, pp. 45-56, 2015.

[3] L.J. Zhou, China's seniors tourism market characteristics and development path, Finance and Economics Theory and Practice, vol.5, pp. 113-118, 2010. 